\title{
A Functional Electrical Stimulation System for Integration in an Exoskeleton
}

DOI: $10.17691 / \mathrm{stm} 2018.10 .3 .12$

ReceivedMarch 26, 2018

1. A. Kastalskiy, PhD, Researcher, Laboratory for the Development of Intellectual Biomechatronic Technologies,

Center for Translational Technologies';

M.A. Khoruzhko, Engineer, Laboratory for the Development of Intellectual Biomechatronic Technologies,

Center for Translational Technologies ${ }^{1}$;

D.V. Skvortsov, MD, DSC, Professor, Department of Rehabilitation, Sports Medicine and Physical Training²;

Leading Researcher, Laboratory for the Development of Intellectual Biomechatronic Technologies,

Center for Translational Technologies ${ }^{1}$

Lobachevsky State University of Nizhni Novgorod, 23 Prospekt Gagarina, Nizhny Novgorod,

603950, Russia;

${ }^{2}$ Pirogov Russian National Research Medical University, 1 Ostrovitianov St., Moscow,

117997, Russia

Currently, there are no exoskeletons with an integrated functional electrical stimulation (FES) system presented on a medical market except for stationary systems.

The aim of the study was to develop FES system, which can be initially integrated in a lower limb exoskeleton to provide the best compatibility and synchronization of the system operation with exoskeleton joints when a patient is moving.

Results. We have developed FES system and the approach to integrate it in an exoskeleton. FES provides for simultaneous work of 2-4 stimulation channels, each of which supports the setting of signal parameters (frequency, amplitude, duration). On-off stimulation time depends on a walking cycle determined by the gait classification algorithm. The presence of synchronizing signals for the left and the right sides provides FES coordinated operation in both lower limbs of a patient. The sphere of application of an exoskeleton with an integrated FES is medical rehabilitation.

Key words: functional electrical stimulation; rehabilitation; exoskeleton; locomotor system disorder.

\section{Introduction}

Primarily, a lower limb exoskeleton was being developed as a device to replace missing motor and supporting function of lower limbs in patients with complete lower limb paralysis. Most existing exoskeletons are designed just for this type of patients.

Currently, lower limb exoskeletons are being developed and manufactured by several dozens of companies worldwide. If the first exoskeleton models made patients legs move and were designed for patients with complete lower limb paralysis, further evolution of exoskeletons was related to nosology expansion.

In our opinion, a true rehabilitation exoskeleton is to be considered in case it can be used both for substitution (prosthetic function) and function recovery. Recent researches have shown that exoskeletons can be effectively applied in various neurological and orthopedic pathologies (cerebral stroke consequences, conditions after locomotor system injuries, and some others) [13]. In this case such exoskeleton capabilities are used to provide normal walking patterns. If an exoskeleton is equipped by a special system of recovering motor activity, it will significantly improve rehabilitation efficiency, as well as extend the application sphere.

For motion recovery, there has been developed a special technology - a functional electrical stimulation (FES). The technique consists in using a therapy course by current pulses for an enforcement action of a stimulated muscle. FES feature is that muscle electrostimulation is possible providing during movements (usually, cyclic), directly at the time when a certain muscle should work at normal [4]. Muscles are activated as a result of muscle motor point (i.e. preserved lower motor neuron) stimulation. Electrical stimulation is combined with performing target exercises $[5,6]$.

Most frequently, FES is used in patients with spinal cord injury (complete or partial). A wide range of FES systems is applied for patients to teach them uprising, standing [7, 8], as well as a supporting system when walking [9-11].

FES still remains the technology, which is technically difficult to implement so far. However, it is the technique, which combines well with the capabilities of a

Corresponding author: Innokenty A. Kastalskiy, e-mail: kastalskiy@neuro.nnov.ru 
rehabilitation exoskeleton, since it helps perform dosing cyclic motions when walking.

In recent years, there have been extensively carried out the researches on fitting exoskeletons with FES system [12-16], however, currently, there are a few ready-made FES systems on a medical market that could be used with exoskeletons. In addition to exoskeletons, active orthosis with FES are being developed $[17,18]$. In fact, an orthosis is a part of an exoskeleton (as a rule, for the knee joint).

The advantages of combined application of FES and an exoskeleton are obvious, therefore, the work on fitting exoskeletons with FES systems started when the latter appeared. Prior to exoskeletons, their precursors were equipped with FES: e.g., such systems as Locomat (Hocoma, Switzerland) and its analogues, stationary exoskeletons. The experience hailed a success, and further work aimed at fitting portable systems, including active orthoses, with FES.

However, meanwhile, only Ekso GT (Ekso Bionics, USA) has a re-equipment option by FES system of an outsourced manufacturer.

For this reason there has been designed an original FES system to be used in rehabilitation exoskeletons.

The aim of the study was to develop functional electrical stimulation system, which can be initially integrated in a lower limb exoskeleton to provide the best compatibility and synchronization of the system operation with exoskeleton joints when a patient is walking.

\section{Materials and Methods}

Based on integrated literature data and own expertise of designing similar systems [19], we have developed a concept of FES system suitable for being integrated in a lower limb exoskeleton. The system includes 2 or 4 FES channels, each channel being implemented in the form of a printed-component board (Figure 1). FES channels enable to deliver a stimulating current to target patient's muscles using body electrodes connected to an equipment connector. Each FES channel has the following technical data of an output signal:

stimulation pulse - U-shaped, with plumb fronts;

current amplitude $-0-100 \mathrm{~mA}$ in increments of $1 \mathrm{~mA}$;

pulse frequency $-25-100 \mathrm{~Hz}$ in increments of $1 \mathrm{~Hz}$;

pulse duration - 2-500 ms in increments of $1 \mathrm{~ms}$ (for a bidirectional signal the duration is symmetrical).

An experimental setup for FES channel testing was assembled (Figure 2).

FES system board is connected to a computer through a USB-port, and a system output is connected to a measuring input of an oscillograph. The functions of amplitude and frequency measurements are used in an oscillograph.

Then we carried out a series of experiments to record stimulating signals in a different variation of parameters in minimum and maximum boundary limits.

To test the capability of reaching effective stimulation current, we added a ballast load (resistance: $270 \mathrm{Ohm}$ ) to FES electrodes. A visual inspection of the assembling correctness was followed by power supply, a series of experiments being carried out to check effective simulation current at different voltage amplitude, oscillating frequency, and width of a stimulation pulse.

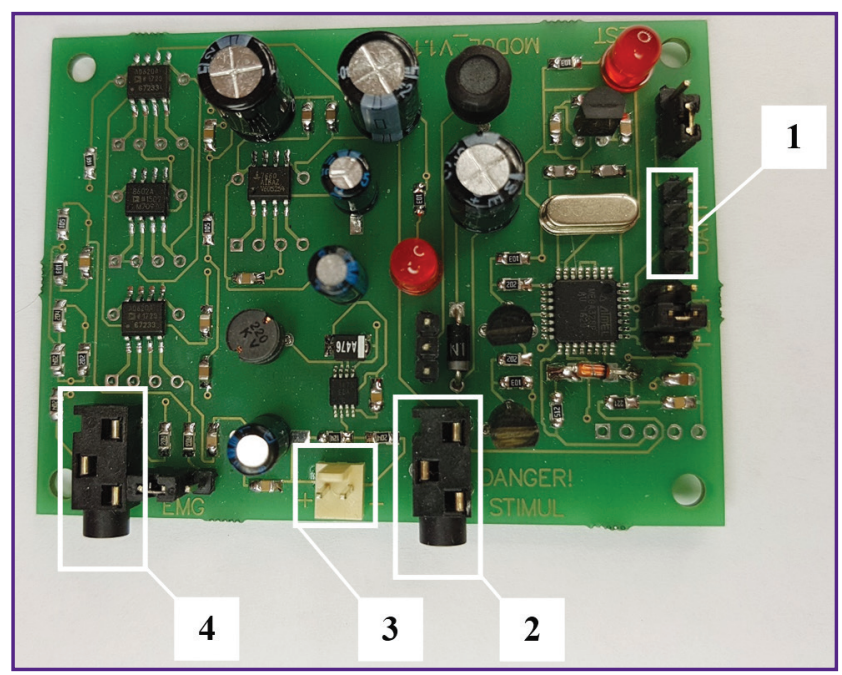

Figure 1. Appearance of channel board of functional electrical stimulation of muscles:

1 - UART-interface control connector; 2 - socket outlet to connect body electrodes to FES system; 3 - FES board power connector; $4-$ a connector to wire up body electrodes to electromyographic activity recording system

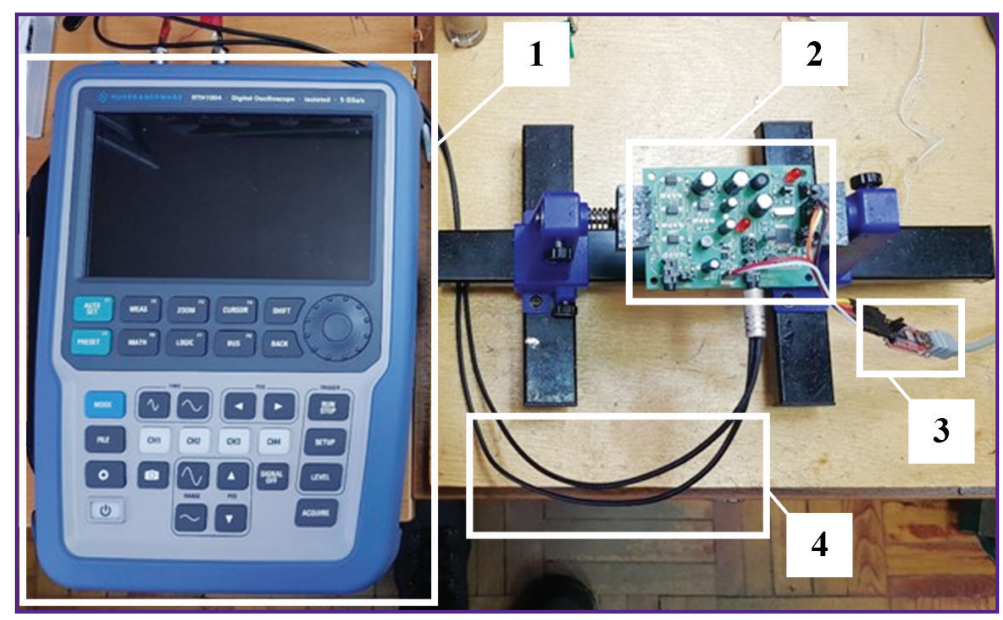

Figure 2. Appearance of an experimental unit to test FES system: 1 - oscillograph; 2 - FES system board; 3 - converter board of interface USB/UART with built-in power supply; 4 - trunk lines to connect oscillograph input and FES board output 


\section{Results}

The Table presents experimental measurement findings.

The experimental findings have shown that the measured parameters are within a tolerance range for the parameters.

The oscillograph recorded FES pulse form and sequence. Figure 3 shows the result of the channel operation at pre-set parameters: amplitude, $90 \mathrm{~V}$; pulse repetition frequency, $100 \mathrm{~Hz}$; pulse width, $500 \mu \mathrm{s}$.

Plumb signal front complies with the requirement of

Stimulating signal characteristics acquired during FES testing

\begin{tabular}{lcccccccc}
\hline \multirow{1}{*}{ Parameters } & \multicolumn{10}{c}{ Experiment number } \\
& $\mathbf{1}$ & $\mathbf{2}$ & $\mathbf{3}$ & $\mathbf{4}$ & $\mathbf{5}$ & $\mathbf{6}$ & $\mathbf{7}$ & $\mathbf{8}$ \\
\hline Amplitude $(\mathrm{V})$ & 88.16 & 88.63 & 88.16 & 88.47 & 30.07 & 30.2 & 30.4 & 30.15 \\
\hline Frequency (Hz) & 25 & 25 & 100 & 100 & 25 & 25 & 100 & 100 \\
\hline $\begin{array}{l}\text { Pulse width ( } \mu \mathrm{s}) \\
\text { Stimulation electric }\end{array}$ & 20 & 500.4 & 20.1 & 505.1 & 19.6 & 499.6 & 20.1 & 502.1 \\
current (mA) & 242 & 245 & 240 & 244 & 250 & 250 & 240 & 249 \\
\hline
\end{tabular}

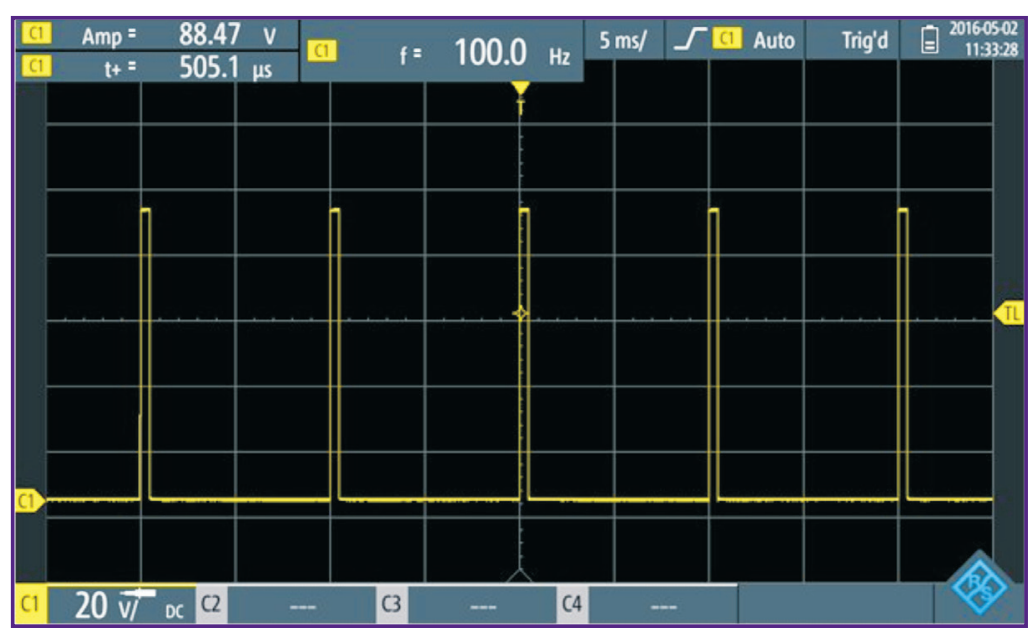

Figure 3. Oscillogram of pulse burst at amplitude, $90 \mathrm{~V}$; pulse repetition frequency, $100 \mathrm{~Hz}$; pulse width, $500 \mu \mathrm{s}$

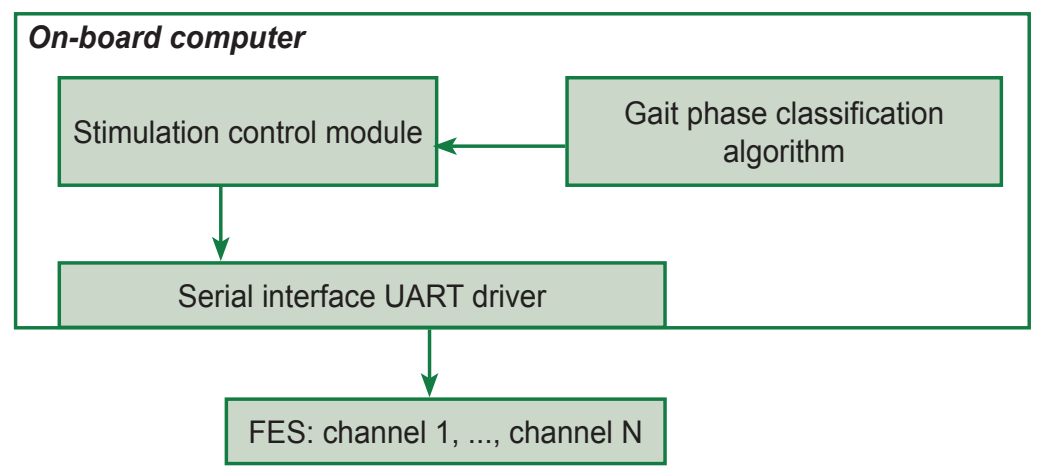

Figure 4. Stimulation control system implementation scheme quickest possible repolarization and enables to make a maximum clinical effect.

To check FES system operation, it was integrated in exoskeleton structure designed before [20]. Electrical stimulation was achieved by means of special skin electrodes. Electrodes depending on a patient's clinical status can be also placed at the fixation areas of exoskeleton cuffs, which can cause electrodes damage. Cables connected to the electrodes can also be damaged by the cuffs. Moreover, the cables guiding to distant devices can be damaged exoskeleton while in drive operation. Another considerable cause of the necessity to integrate FES system in an exoskeleton is the requirement of implied real-time FES synchronization with exoskeleton movements to a high precision. Figure 4 shows an electric stimulation scheme.

Electrical stimulation support system includes several one-duct banks (powered by 2-4 stimulation channels) and software controlling the stimulation process. FES blocks are mounted on an exoskeleton frame adjacent to the attachment point of electrodes to fix possible leakage, reduce electromagnetic interference in stimulation and shorten the cable length.

The software under the control of Linux operating system on a single-board computer of the exoskeleton provides a stimulation control system. Stimulation control is provided as follows. Classification algorithm determines gait phases according to electromyography findings and transmits a synchronization signal to the stimulation control module. The synchronization signal is a key signal for all FES channels of one side (left or right). Thus, there are separate synchronization signals for a walking cycle of the right and the left lower limb. A synchronization signal determines the walking cycle beginning moment of the leg. The programming of each FES channel provides the setting of the following parameters:

pulse frequency;

pulse amplitude;

duration of a single pulse;

starting work time relating to the beginning of a walking cycle;

finishing work time relating to the beginning of a walking cycle.

The first three parameters determine the intensity of the effect and are adjusted considering patient's sensations during channel test run. The intensity should be such there was a visible contraction of a stimulated muscle, though in the limits 
of tolerable pain sensations. The last two parameters determine time schedule of the channel operation. Time schedule of the channel operation for a stimulated muscle is adjusted according to the program of muscular stimulation in accordance with the data published before [19].

FES channels are switched on-off-on an operator's command. After switching, FES channels work automatically according to pre-set parameters and a synchronization signal.

\section{Conclusion}

The expansion of exoskeleton application sphere suggests both: walking simulation as locomotion, i.e., function replacement, and also the recovery of lost capabilities to walk. In addition, the use of an auxiliary drive is not always enough. In order to enhance a rehabilitation effect, exoskeletons are equipped with an additional FES system that significantly improves a clinical effect. However, there are no exoskeleton models with an integrated FES system, and the use of external systems is limited.

We have suggested the solution consisting in developing an original FES system designed for integration in an exoskeleton. Technical implementation of the solution seems to be promising and requires its further improvement.

Study funding. The research was supported by Ministry of Education and Science of the Russian Federation as part of Federal Targeted Programme "Research and Development in Priority Areas of Development of the Russian Scientific and Technological Complex for 2014-2020". Grant Agreement No.14.578.21.0107 dated 27.10.2015 (Project unique identifier RFMEFI57815X0107).

Conflicts of interest. The authors declare no conflicts of interest related to the present study.

\section{References}

1. Hill D., Holloway C.S., Morgado Ramirez D.Z., Smitham P., Pappas Y. What are user perspectives of exoskeleton technology? A literature review. Int J Technol Assess Health Care 2017; 33(2): 160-167, https://doi. org/10.1017/s0266462317000460.

2. Fukaya T., Mutsuzaki H., Yoshikawa K., Sano A., Mizukami M., Yamazaki M. The training effect of early intervention with a hybrid assistive limb after total knee arthroplasty. Case Rep Orthop 2017; 2017: 6912706, https:// doi.org/10.1155/2017/6912706.

3. McGibbon C.A., Brandon S.C.E., Brookshaw M., Sexton A. Effects of an over-ground exoskeleton on external knee moments during stance phase of gait in healthy adults. Knee 2017; 24(5): 977-993, https://doi.org/10.1016/j.knee. 2017.04.004.

4. Thrasher T.A., Popovic M.R. Functional electrical stimulation of walking: function, exercise and rehabilitation.
Ann Readapt Med Phys 2008; 51(6): 452-460, https://doi. org/10.1016/j.annrmp.2008.05.006.

5. Dimitrijevic M.M., Dimitrijevic M.R. Clinical elements for the neuromuscular stimulation and functional electrical stimulation protocols in the practice of neurorehabilitation. Artif Organs 2002; 26(3): 256-259, https://doi.org/10.1046/j.15251594.2002.06946.x.

6. Bijak M., Rakos M., Hofer C., Mayr W., Strohhofer M., Raschka D. Stimulation parameter optimization for FES supported standing up and walking in $\mathrm{SCl}$ patients. Artif Organs 2005; 29(3): 220-223, https://doi.org/10.1111/j.15251594.2005.29039.x.

7. Matjacic Z., Bajd T. Arm-free paraplegic standing part II: experimental results. IEEE Trans Rehabil Eng 1998; 6(2): 139-150, https://doi.org/10.1109/86.681179.

8. Holderbaum W., Hunt K.J., Gollee H. $\mathrm{H}_{\infty}$ robust control design for unsupported paraplegic standing: experimental evaluation. Control Eng Pract 2002; 10(11): 1211-1222, https:// doi.org/10.1016/S0967-0661(02)00082-5.

9. Thrasher T.A., Flett H.E., Popovic M.R. Gait training regimen for incomplete spinal cord injury using functional electrical stimulation. Spinal Cord 2006; 44(6): 357-361, https://doi.org/10.1038/sj.sc.3101864.

10. Kralj A., Bajd T., Turk R. Enhancement of gait restoration in spinal injured patients by functional electrical stimulation. Clin Orthop Relat Res 1988; 1998(233): 34-43, https://doi.org/10.1097/00003086-198808000-00006.

11. Graupe D., Davis R., Kordylewski H., Kohn K.H. Ambulation by traumatic T4-12 paraplegics using functional neuromuscular stimulation. Crit Rev Neurosurg 1998; 8(4): 221-231, https://doi.org/10.1007/s003290050081.

12. Mazzoleni S., Battini E., Rustici A., Stampacchia G. An integrated gait rehabilitation training based on functional electrical stimulation cycling and overground robotic exoskeleton in complete spinal cord injury patients: preliminary results. IEEE Int Conf Rehabil Robot 2017; 2017: 289-293, https://doi.org/10.1109/icorr.2017.8009261.

13. Ha K.H., Murray S.A., Goldfarb M. An approach for the cooperative control of FES with a powered exoskeleton during level walking for persons with paraplegia. IEEE Trans Neural Syst Rehabil Eng 2016; 24(4): 455-466, https://doi. org/10.1109/TNSRE.2015.2421052.

14. Alibeji N.A., Kirsch N.A., Sharma N. A muscle synergyinspired adaptive control scheme for a hybrid walking neuroprosthesis. Front Bioeng Biotechnol 2015; 3: 203, https:// doi.org/10.3389/fbioe.2015.00203.

15. del-Ama A.J., Gil-Agudo A., Pons J.L., Moreno J.C. Hybrid FES-robot cooperative control of ambulatory gait rehabilitation exoskeleton. J Neuroeng Rehabil 2014; 11(1): 27, https://doi.org/10.1186/1743-0003-11-27.

16. Ha K.H., Quintero H.A., Farris R.J., Goldfarb M. Enhancing stance phase propulsion during level walking by combining FES with a powered exoskeleton for persons with paraplegia. Conf Proc IEEE Eng Med Biol Soc 2012; 2012: 344-347, https://doi.org/10.1109/embc.2012. 6345939.

17. Chang S.R., Kobetic R., Audu M.L., Quinn R.D., Triolo R.J. Powered lower-limb exoskeletons to restore gait for individuals with paraplegia - a review. Case Orthop J 2015; 12(1): 75-80.

18. Chang S.R., Nandor M.J., Li L., Kobetic R., Foglyano K.M., Schnellenberger J.R., Audu M.L., Pinault G., Quinn R.D., Triolo R.J. A muscle-driven approach to restore 


\section{CLINICAL MEDICINE}

stepping with an exoskeleton for individuals with paraplegia. J Neuroeng Rehabil 2017; 14(1): 48, https://doi.org/10.1186/ s12984-017-0258-6.

19. Vitenzon A.S., Petrushanskaya K.A., Skvortsov D.V. Rukovodstvo po primeneniyu metoda iskusstvennoy korrektsii khodby $i$ ritmicheskikh dvizheniy posredstvom programmiruemoy elektrostimulyatsii myshts [Manual on the use of the method of artificial correction of walking and rhythmic movements through programmed electrical stimulation of muscles]. Moscow; 2004; 284 p.

20. Mineev S.A., Novikov V.A., Kuzmina I.V., Shatalin R.A., Grin I.V. Goniometric sensor interface for exoskeleton system control device. Biomed Eng 2016; 49(6): 357-361, https://doi. org/10.1007/s10527-016-9566-6. 